\title{
Evaluation of the anticorrosion performance of peel garlic extract as corrosion inhibitor for ASTM 1020 carbon steel in acidic solution
}

\author{
Lhaira Souza Barreto ${ }^{1}$, Mirian Sanae Tokumoto ${ }^{1}$, Isabel Correia Guedes ${ }^{2}$, \\ Hercílio Gomes de Melo $^{2}$, Franco Dani Rico Amado ${ }^{1}$, Vera Rosa Capelossi ${ }^{1}$
}

\author{
${ }^{1}$ Laboratório de Materiais e Meio Ambiente- LAMMA- UESC CEP: 45662-90, Ilhéus, Ba e-mail: lhairabarre- \\ to@gmail.com, miriam.tokumoto@gmail.com, franco.amado@gmail.com, vera.rosa@gmail.com \\ ${ }^{2}$ Laboratório de Processos Eletroquímicos - LPE - USP CEP: 05508-030, São Paulo, SP e-mail: icgue- \\ des.usp@gmail.com, hgdemelo@usp.br
}

\begin{abstract}
Metallic corrosion can be delayed using corrosion inhibitors. However, several industrial corrosion inhibitors are toxic and harmful to the environment and to the human health. In this context, in the last decades, research has been developed to investigate the performance of low toxicity corrosion inhibitors as green inhibitors obtained from vegetables, which are environmentally acceptable. The present work studied the corrosion inhibition efficiency of peel garlic extract (Allium sativum. L.) for possible replacement of benzotriazole (BTAH) on the corrosion inhibition of ASTM 1020 carbon steel (CS-1020) in 0.5 mol.. $\mathrm{L}^{-1}$ hydrochloric acid media. Weight loss measurements, anodic and cathodic potentiodynamic curves and electrochemical impedance (EIS) experiments were carried out. The Fourier transformed infrared spectroscopy (FTIR) was carried out to evaluate the chemical compounds. The morphological characterization was obtained to observe the inhibitor effect in the corrosion products on substrate surface. The results showed that the addition of both inhibitors effectively hinder the corrosion process and indicated their adsorption on the electrode surface. The inhibiting efficiency of the peel garlic extract was only slightly inferior to BTAH showing that the former inhibitor can be an environmentally friendly option to toxic inhibitors. The FTIR analysis showed the presence of chemical compounds which presents antioxidant properties.
\end{abstract}

Keywords: Corrosion, corrosion inhibitors, Allium sativum. L., benzotriazole, EIS

\section{INTRODUCTION}

Corrosion is a phenomenon resulting in materials deterioration through chemical or electrochemical interaction with the environment. This process may compromise the mechanical and physical properties of equipments with serious economic and environmental impact in all infrastructure sectors, such as roads, oil and gas pipelines, construction and water and sewage systems, causing severe damage and threats to public safety and health [1].

Carbon steel, due to its mechanical properties and low cost, is widely used in industry. However, this material has low corrosion resistance, reducing the performance and useful life of engineering products. Therefore, it is necessary to apply methodologies that act against the corrosion process, for instance pretreatments and corrosion inhibitors application.

Organic corrosion inhibitors are a class of molecules that delay or minimize the corrosive process. It has been shown that their effectiveness is mainly related to adsorption on the metal surface [2], acting as a barrier layer and reducing aggressive species access [3]. According to the literature, usually, they get adsorbed on the metal surface by displacing water molecules [4] and the bonding efficiency is enhanced by the presence of polar functions with $\mathrm{S}, \mathrm{O}$ or $\mathrm{N}$ atoms in the molecule, heterocyclic compounds and $\pi$ electrons [5].

Benzotriazole (BTAH) is widely used as corrosion inhibitor due to its ability to form a protective film on different metallic materials and the literature demonstrates that it can effectively hinder steel corrosion in several media [6]. However, currently, there are controversies regarding the toxicity of this inhibitor towards humans and the environment [7]. Therefore, industries and researchers are broadening their efforts to develop 
corrosion inhibitors formulations presenting low toxicity and good efficiency.

Recent researches in the corrosion area have focused in the use of natural corrosion inhibitors extracted from plants [8], seeds [9], natural herbs [10] and medicinal plants [11]. These are biodegradable, sustainable, easily available and low cost substances. In addition, they do not contain toxic compounds [12]. Many reports on the successful use of these substances to prevent corrosion of different metals in acidic media are available. For instance, Alsabagh et al. [13] report that green tea extracts could effectively diminish the corrosion rate of carbon steel in $\mathrm{HCl}$ and $\mathrm{H}_{2} \mathrm{SO}_{4}$ media, being more effective in the former than in the latter, Fouda et al. [14] found that Hyoscyamus muticus extract could be effective for copper corrosion inhibitor in $\mathrm{HNO}_{3}$ and Obot and Obi-Egbedi [15] indicate that leaf extracts of Chromolaena odorata L. can effectively diminish $\mathrm{Al}$ corrosion in $2 \mathrm{M} \mathrm{HCl}$.

Allium sativum $L$. is an herbaceous plant from the Liliace family species with characteristics taste and odor. It is widely used in cooking and for therapeutic purposes all over the world [4]. Studies show that the chemical composition of garlic is rich in starch, aromatic substances and sulphur derivatives [16], which can improve their adsorption onto metallic surfaces. In the literature, there are only few works where the corrosion inhibition properties of garlic have been tested. For aluminum, it has been verified that it can hinder corrosion both in acidic [17] and basic [18] media. For carbon steel, Afia et al. [19] have found that essential oil obtained from green garlic plant was effective in reducing the metal corrosion in de aerated $\mathrm{HCl} 1 \mathrm{~mol} . \mathrm{L}^{-1}$, whereas Rodriguez-Clement et al.[4] report that extract obtained from chopped and soaked garlic bulbs were efficient in inhibiting carbon steel corrosion in $\mathrm{H}_{2} \mathrm{SO}_{4} 0.5$ mol. $\mathrm{L}^{-1}$.

Considering the interest of preserving carbon steel structures and to obtain a low toxicity inhibitor, this study aims to evaluate the behavior of a natural corrosion inhibitor obtained from garlic peel (Allium sativum L.) for a possible replacement of benzotriazole (BTAH) on the corrosion protection of 1020 carbon steel $(\mathrm{CS}-1020)$ in acidic medium $\left(0.5 \mathrm{~mol} . \mathrm{L}^{-1} \mathrm{HCl}\right)$.

\section{MATERIALS AND METHODS}

The investigation was performed with carbon steel 1020 (CS-1020) immersed in $\mathrm{HCl} 0.5$ mol.L $\mathrm{L}^{-1}$ (anidrol) without and with inhibitor. Prior to any test, the samples surfaces were sequentially ground with 120,320 , 400, 600, 800, 1200 and 2000 sand paper and then washed with distilled water, ethanol and acetone and dried with a hot air stream.

To prepare the extract the garlic peel was initially washed in distilled water and dried in an oven at $70^{\circ} \mathrm{C}$ for $60 \mathrm{~min}$. Next, the dried samples were milled, to reduce the particle size to a powder, and immersed in ethanol at room temperature for $48 \mathrm{~h}$. The mixture was then filtered and the concentrated extract produced using a rotary evaporator at $79^{\circ} \mathrm{C}$ to remove the excess solvent, resulting in the extract powder. Preliminary tests were carried out using two different concentrations of the peel garlic extract: $0.778 \mathrm{~g} \mathrm{~L}^{-1}$ and $1.112 \mathrm{~g} \mathrm{~L}^{1}$. Weight loss measurements were performed according to ASTM G1 [20] using rectangular samples $(50 \mathrm{x} 20 \mathrm{x}$ $0.8) \mathrm{mm}$. Weighing was carried out every $2 \mathrm{~h}$, after the samples have been washed with distilled water, alcohol and acetone. All the electrochemical impedance spectroscopy (EIS) experiments were carried out using a potentiostat/galvanostat AUTOLAB type PGSTAT302N, equipped with an impedance modulus and controlled with the ANOVA 10.0 software. The diagrams were acquired at the open circuit potential $\left(\mathrm{E}_{\text {ocp }}\right)$ after 90 min. stabilization using a classical three electrodes mounting. Round-shaped $\left(1.0 \mathrm{~cm}^{2}\right) \mathrm{CS}-1020$ samples were employed as working electrodes with a Rh-coated $\mathrm{Ti}$ wire as auxiliary electrode and an $\mathrm{Ag} / \mathrm{AgCl}|| \mathrm{KClSat}$ reference electrode. The data were obtained from $100 \mathrm{kHz}$ to $10 \mathrm{mHz}$, with 10 points per decade using a perturbation amplitude of $10 \mathrm{mV}$. For quantitative analyses, EIS data were fitted with the Zview software.

Anodic and cathodic polarization curves were acquired from $\mathrm{OCP} \pm 250 \mathrm{mV}$ using a three electrode cell as described previously. The experiments were performed with AUTOLAB type PGSTAT302N at a scan rate of $0.5 \mathrm{mV} \mathrm{s}^{-1}$. The curves were acquired subsequently to the EIS measurements after $5 \mathrm{~min}$ of stabilization of the OCP.

Micrographs of the electrodes surface were taken after 110 min immersion in the test electrolyte with and without the inhibitors using a scanning electron microscope (SEM) Quanta 250F after weight loss measurements and EIS experiments. Semi quantitative analysis of the surface composition was performed by electron dispersive spectroscopy (EDS) attached to the SEM.

The chemical characterization of the peel garlic extract and benzotriazole (Merck S/A) powders was obtained by infrared spectroscopy (FTIR) using a Thermo Scientific Nicolet spectrometer model is10. Spec- 
tra were recorded at room temperature in the wave number range $4000-400 \mathrm{~cm}^{-1}$ at a resolution of $4 \mathrm{~cm}^{1}$.The powders were analysed using $\mathrm{KBr}$ pellets.

\section{RESULTS AND DISCUSSION}

\subsection{FTIR Characterization}

Figures 1 and 2 show, respectively, the FTIR spectra acquired from the peel garlic extract and benzotriazole (BTAH) powder.

The intense band in the region of $3396 \mathrm{~cm}^{-1}$ relative to $\mathrm{OH}$ groups, present only in the peel garlic extract spectrum (Fig.1), indicates that the ethanol used for its production was not completely removed. Other important bands in this spectrum, are the one at $1718 \mathrm{~cm}^{-1}(\mathrm{C}=\mathrm{O})$, and those between $1240 \mathrm{~cm}^{-1}$ and 1636 $\mathrm{cm}^{-1}$, corresponding to organic compounds containing nitrogen and sulfur. Other specific bands ascribed to sulfur containing compounds were also detected at $720 \mathrm{~cm}^{-1}(\mathrm{CS}), 1044 \mathrm{~cm}-1$ ( $\left.\mathrm{S}=\mathrm{O}\right)$ and at $1235 \mathrm{~cm}^{-1}$ (SS) [21].According to Gomes [22], OH groups facilitate the adsorption of organic substances on metal surfaces by tending to form hydrogen bonds with free radical of carbon, nitrogen and sulfur compounds normally present in these molecules. This author also assigns inhibitive properties to $\mathrm{C}=\mathrm{O}$ groups for carbon steel [21]. Finally, according to Zucchi et al. [23], organic compounds containing nitrogen and sulfur can act as corrosion inhibitor due to their antioxidant properties. The corrosion-inhibiting effect of peel garlic extract can be attributed to phytochemical constituents including alkaloids, carboxylic acids, ketenes and alcohols. The different constituents may react with freshly generated $\mathrm{Fe}^{2+}$ ions on a corroding metal surface forming organometallic [Fe-Inh] complexes [23]. This must results in the reduction of carbon steel corrosion rate due to the organic compound of peel garlic extract probably adsorbed on the metal surface, protecting the metal from corrosion attack.

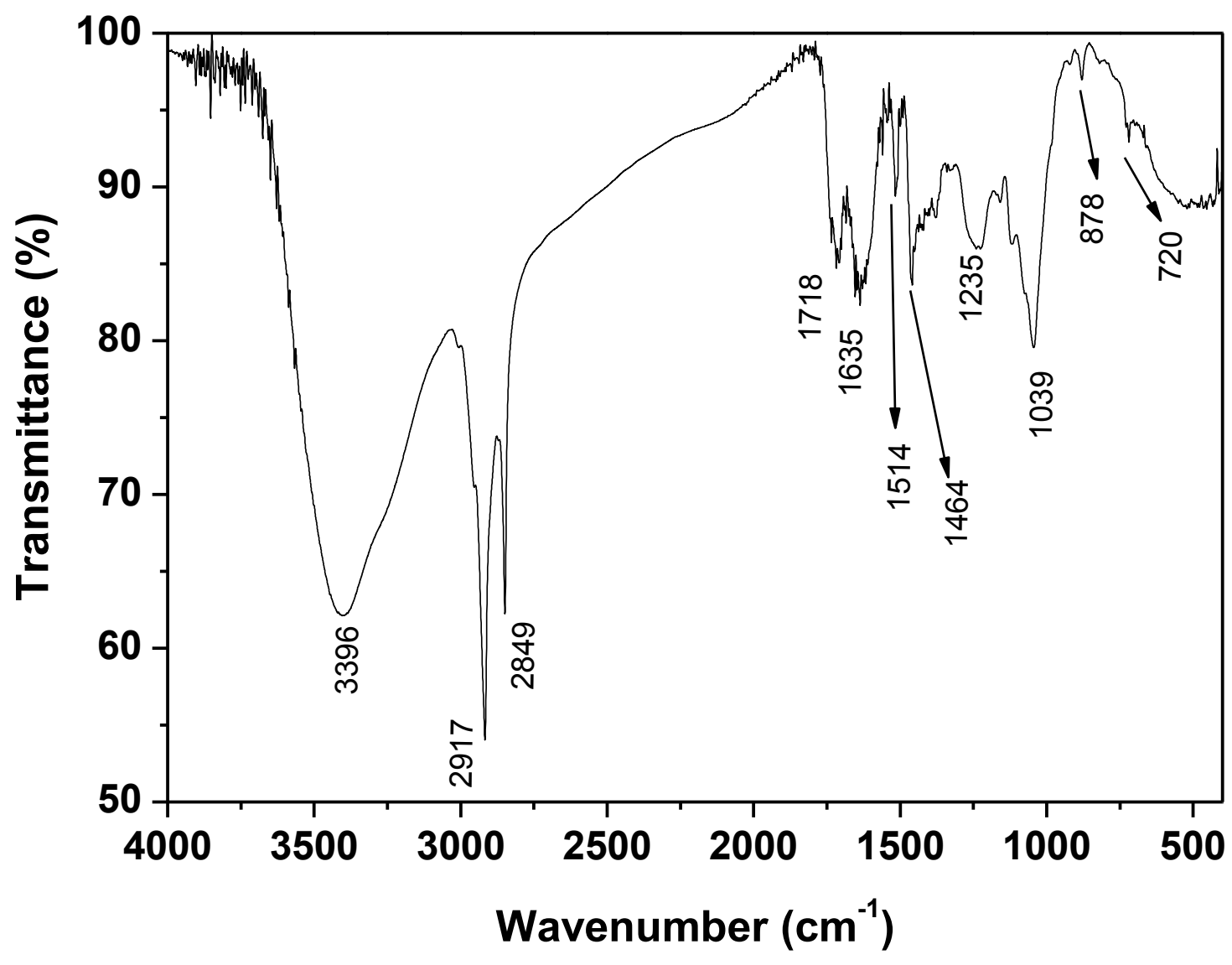

Figure 1: Infrared spectrum of the garlic peel extract. 


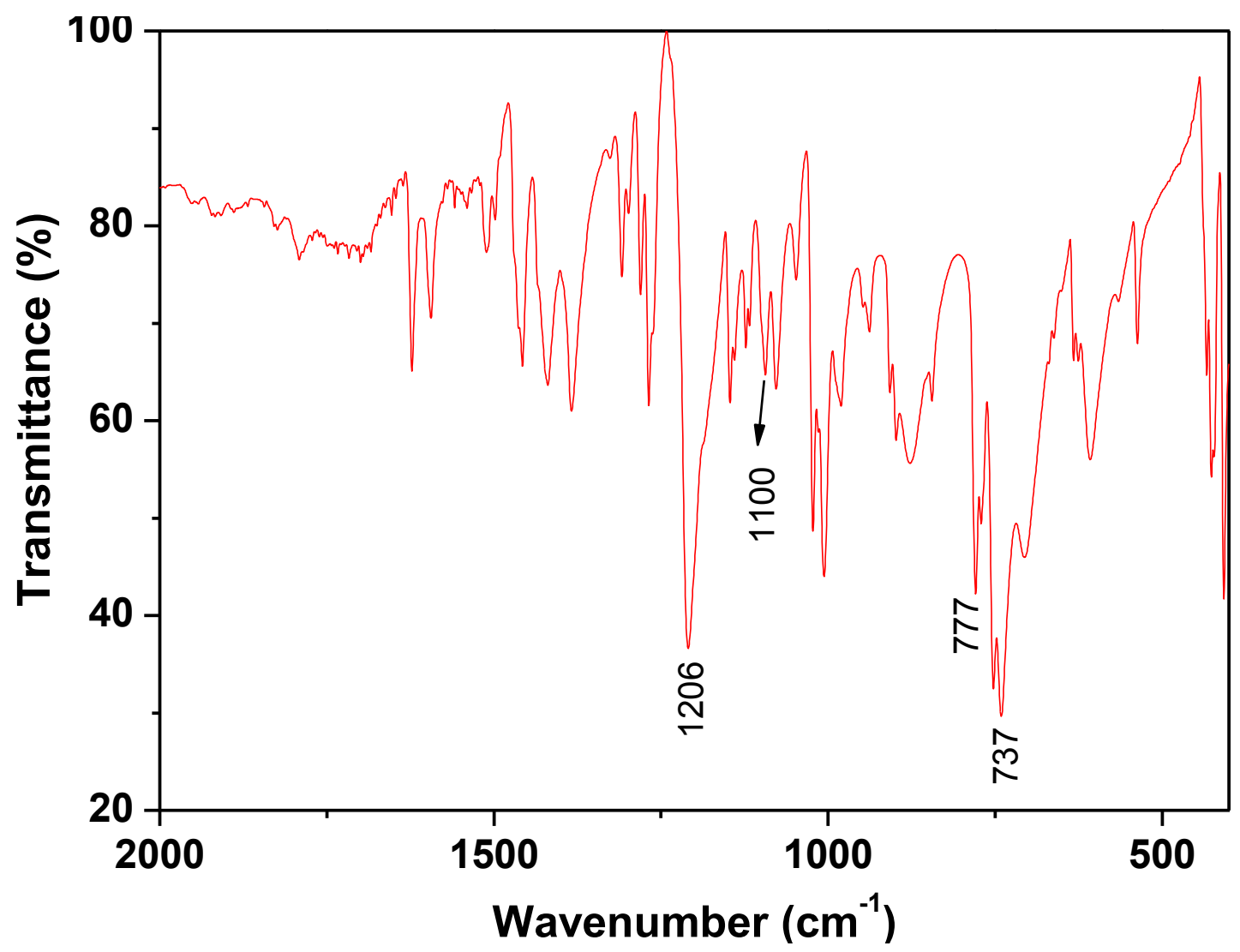

Figure 2: Infrared spectrum of the benzotriazole powder.

A fully identified FTIR spectrum for BTAH is presented in Figure 2. Being a pure compound, peaks assignments were easier than for garlic peel extract. In the spectrum the most relevant bands are those observed at 1206,777 and $737 \mathrm{~cm}^{-1}$, corresponding to the $\mathrm{C}-\mathrm{H}$ in-plane bending and $\mathrm{C}-\mathrm{H}$ out-of-plane bending vibrations of the benzotriazole benzene ring. At $1100 \mathrm{~cm}^{-1}$ there is another important peak that can be attributed to the stretching of benzene and triazole rings, corresponding also to N-H stretching.

The FTIR spectra of the peel garlic extract and BTAH powders evidenced the presence of some compounds with antioxidant properties, namely: sulfur and nitrogen for garlic peel (Fig. 1) and nitrogen for BTAH (Fig. 2) [3, 21]. As already stated in the introduction, the presence of these atoms favor the adsorption of organic molecules to metallic surfaces enhancing their inhibiting properties $[22,23]$.

BTAH is an heterocyclic nitrogen-containing organic compound, which chemical structure is widely known [25]. On the other hand, in the complex composition of Allium a large number of organosulfur [17] as well as nitrogen containing molecules have been identified. Therefore, in the garlic peel extract two functionalities with potentially inhibiting properties were identified.

\subsection{Weight loss experiments}

The inhibition efficiency (IE) and the corrosion current density were determined from gravimetric tests after 2 hours immersion in the different electrolytes. IE was calculated from equation (1), where $W_{\text {corr }}(w / 0)$ and $W_{\text {corr }}(\mathrm{w})$ correspond, respectively, to the weight loss without and with the inhibitor [25]:

$$
I E=\frac{W_{\text {corr }(\text { wo })}-W_{\operatorname{corr}(\mathrm{w})}}{W_{\operatorname{corr}(\mathrm{wo})}} \times 100
$$

Where as the corrosion current density was determined from equation (2):

$$
i_{\text {corr }}=w_{\text {corr }} \frac{96500}{E_{\text {qmetal }}}
$$


where $i_{\text {corr }}$ is the corrosion current density $\left(A \mathrm{~cm}^{-2}\right), w_{\text {corr }}$ the corrosion rate $\left(\mathrm{g} \mathrm{cm}^{-2} \mathrm{~h}^{-1}\right), 96500$ the Faraday's constant (A s) and $E_{\text {qmetal }}$ the equivalent gram of iron, $27.939 \mathrm{~g}$ [25].

The results of the weight loss determinations after the completion of the experiments, together with the values calculated from equation (1) and (2) are summarized in Table 1.

They evidence that corrosion of CS occurs when immersed in $0.5 \mathrm{~mol} \mathrm{~L}^{-1} \mathrm{HCl}$ solution; however, the process is minimized in the presence of the inhibitors. Concerning the garlic peel extract, it can be verified that the inhibiting power increases when greater amount is added to the electrolyte. Such behavior may be justified by the presence of antioxidant molecules in the garlic peel extract that adsorb in the substrate surface, thus retarding the corrosive process. [6]

The last column of Table 1 display the inhibition efficiency calculated from the weight loss measurements. It can be verified that, for the same amount of inhibitor, BTAH is slightly more efficient than the garlic peel extract. However, taking into account that the composition of the extract must be quite complex, it can be supposed that active inhibitors components of the garlic peel extract must be very effective. Regarding the determined inhibiting efficiency that for BTAH is in accordance with published results [4], whereas for the garlic peel extract no data is available in the literature.

Table 1: Weight loss of CS - ASTM 1020 after 2 hours immersion in $0.5 \mathrm{~mol} . \mathrm{L}^{-1} \mathrm{HCl}$ in the absence and in the presence of inhibitors.

\begin{tabular}{l|l|l|l}
\hline MEDIUM & VARIATION (G) & $\mathbf{W}_{\text {CORR }}\left(\mathbf{G} \cdot \mathbf{C M}^{-2} \cdot \mathbf{H}^{-1}\right)$ & $\mathbf{N}(\%)$ \\
\hline Without inhibitor & $1,30 \times 10^{-2}$ & $5,43 \times 10^{-4}$ & \\
\hline & & & \\
$1,112 \mathrm{~g} . \mathrm{L}^{-1} \mathrm{extract}$ & $1,0 \times 10^{-3}$ & $4,17 \times 10^{-5}$ & 90,65 \\
\hline & $6,33 \times 10^{-4}$ & $2,64 \times 10^{-5}$ & \\
$1,112 \mathrm{~g} . \mathrm{L}^{-1} \mathrm{BTAH}$ & & & 95,14 \\
\hline
\end{tabular}

\subsection{ELECTROCHEMICAL TECHNIQUES}

\subsubsection{Electrochemical impedance spectroscopy (EIS)}

Figure 3 exhibits the results of the EIS experiments acquired at the open circuit potential after 90 minutes of immersion in the different test electrolytes. As for other organic corrosion inhibitors for steel in acidic solutions [26], the diagrams are composed by a single depressed capacitive loop, showing that a sole charge transfer process is taking place at the electrode surface, which, as indicated by the unaltered diagrams shapes, is unaffected by the addition of the inhibitors to the electrolyte. The fact that only one loop is present in the diagrams for the inhibitors containing solutions indicates that the molecules adsorption occurs by simple surface coverage [26], as for a film forming inhibitor a supplementary high frequency time constant would be expected. Moreover, the deviation of the loop from a perfect semicircle is a consequence of Cole-Cole time constant dispersion, frequently attributed to roughness or the presence of heterogeneities at the electrode surface [27]. 

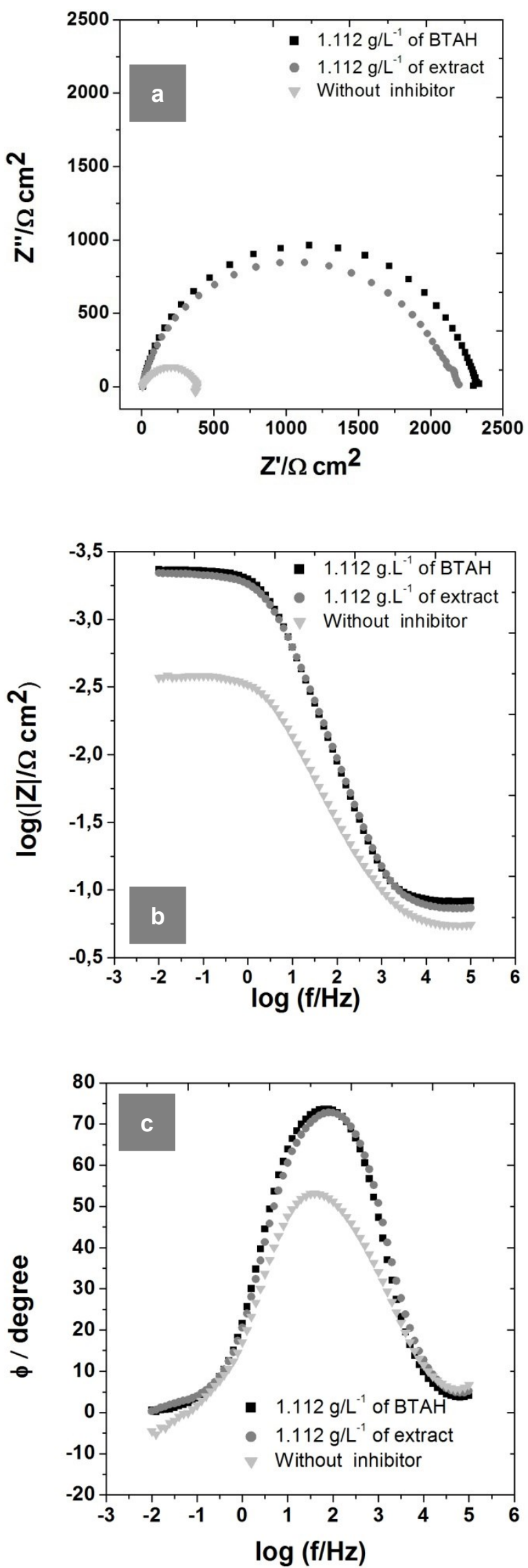

Figure 3: Nyquist (a) and Bode ((b and (c)) diagrams obtained for ASTM 1020 carbon steel, in presence and absence of inhibitors after 90 minutes of immersion in 0.5 mol.L-1 $\mathrm{HCl}$ aqueous solution 
Figure 3 shows that the addition of any of the two inhibitors to the aggressive solution provokes an important increase in the impedance modulus of CS-1020, pointing to an effective corrosion hindrance. Additionally, in the presence of the inhibitors, the capacitive response of the electrode increases, indicating the displacement of charged species from the electrode surface. Both these fact can be ascribed to the adsorption of the surface-active components of peel garlic extract or BTAH to the electrode surface blocking the access of aggressive species and hindering the corrosion reaction [16]. The diagrams also indicate that BTAH is slightly more efficient than the peel garlic extract.

In a single loop impedance diagram, the ability of an inhibitor to protect a metallic substrate from the corrosion process can be evaluated by two parameters: the charge transfer resistance and the double layer capacity [28]. The first one is given by the diameter of the capacitive loop and is inversely related to the reactive surface area of the electrode, i.e., the bigger the diameter the smaller the active surface area and the slower the corrosion reaction. In the present case, this is a consequence of surface blockage by corrosion inhibitor [29] leaving less and/or narrower conductive pathways to the metallic substrate. The second parameter can be easily calculated, either by equivalent electrical circuit fitting or through the determination of the phase angle maximum, and its changes can be directly associated to modifications of the electrical double layer properties due to the presence of the adsorbed inhibitors molecules.

For a more precise quantitative evaluation of the effect of the studied inhibitors in the two previously described parameters, the impedance diagrams were fitted using a classical electrical equivalent circuit frequently used to represent the impedance response of steel in acidic solution (Figure 4). In the circuit Rs represents the solution resistance, Rct, the charge transfer resistance, whereas the double layer capacitance was replaced by a constant phase element $(\mathrm{CPEdl})$. This is frequently required when a non-ideal frequency response is obtained in EIS experiments. In these cases, diagrams are characterized by depressed capacitive loops that centers lay below the real axis [28]. The impedance of a CPE is defined by Eq. (3), wherein Q is the CPE constant, $\omega$ is the angular frequency $\left(\operatorname{rad} . \mathrm{s}^{-1}\right), \mathrm{i}^{2}=-1$ is the imaginary number and $\alpha$ is the CPE exponent [26].

$$
Z_{C P E}=Q^{-1}(i \omega)^{-\alpha}
$$

The results of the fitting procedure are reported in Table 2. In accordance with what has already been stated, the addition of the inhibitors increases the Rct values more than five times when compared with the inhibitor free solution. In addition, this parameter is slightly higher in the BTAH containing electrolyte, confirming that this inhibitor is slightly more efficient than the garlic peel extract. Concerning the CPE behavior, their values substantially decrease in the presence of the inhibitors. According to the Helmholtz model the double layer capacitance is given by equation (4) [26]:

$$
\mathrm{Cdl}=\frac{\varepsilon \varepsilon_{\mathrm{o}}}{\mathrm{d}}
$$

where $\mathrm{Cdl}$ is the thickness of the double layer, $\varepsilon$ is the dielectric constant of the medium and $\varepsilon 0$ is the vacuum permittivity.

The adsorption of the organic inhibitor molecules to the electrode surface displaces water molecules and/or chloride ions [30], thus diminishing the double layer dielectric constant, moreover, due to the molecules sizes, this process also increases the double layer thickness [31]. These two phenomena contribute to diminish the double layer capacity. Therefore, the decrease in the CPE values is a direct consequence of the adsorption of the inhibitors on the CS-1020 surface.

The data presented in Table 2 also show that in the presence of the inhibitor the CPE exponent, " $\alpha$ ", increases. According to the literature $[26,28]$ this can be interpreted as an evidence for surface in homogeneity decrease, which must be a consequence of the protection afforded by the organic molecules.

Using equation (4) [26] IE was calculated from the data obtained from the equivalent electrical circuit fitting procedure:

$$
\mathrm{IE} \%=\frac{\left[\mathrm{R}_{\mathrm{ct}}-\mathrm{R}_{\mathrm{cto}}\right]}{\mathrm{R}_{\mathrm{ct}}} \times 100
$$


where Rcto and Rct are, respectively, the charge transfer resistance in the absence and presence of the inhibitors. The IE calculated using eq. (5) for BTAH and garlic peel extract were, respectively 82.28\% and $81.19 \%$.

Due to the extensive interest in using green corrosion inhibitors to hinder corrosion of carbon steel in acidic media, a number of works have been done where EIS was used to evaluate the IE of plant extracts in hydrochloric acid media. Recent results report a maximum IE of about: $96 \%$ for Jam un seed in $1 \mathrm{~mol} \mathrm{~L}^{-1} \mathrm{HCl}$ after 30 min stabilization of the OCP [9], 97\% from gravimetric measurements and $83.7 \%$ from polarization measurements for nettle extract in $0.5 \mathrm{~mol} \mathrm{~L}^{-1} \mathrm{HCl}$ [32], 93\% for polyphenols extracted from olive mill wastewater in $0.5 \mathrm{~mol} \mathrm{~L}^{-1} \mathrm{HCl}$ after $30 \mathrm{~min}$ stabilization of the OCP [33] and, respectively, of $83 \%$ and $93 \%$ for crude and concentrated grape pomace after $30 \mathrm{~min}$ immersion in $1 \mathrm{~mol} \mathrm{~L}^{-1} \mathrm{HCl}$ [34]. For systems similar to the investigated in the present study, the results are scarcer. Rodriguez-Clemente et al. [4] achieved an IE as high as $96 \%$ in $0.5 \mathrm{~mol} \mathrm{~L}-1 \mathrm{H}_{2} \mathrm{SO}_{4}$ in concentrations included of $1000 \mathrm{ppm}$, and Afia et al. [19] reported an IE approximately of $95.8 \%$ for $2.5 \mathrm{~g} \mathrm{~L}^{-1}$ after $30 \mathrm{~min}$ of immersion in $1.0 \mathrm{~mol} \mathrm{~L}^{-1} \mathrm{HCl}$, which are both higher than that presented in this study. However, in this latter work [19], the extract was obtained from green garlic being different from the formulation employed in the present work.

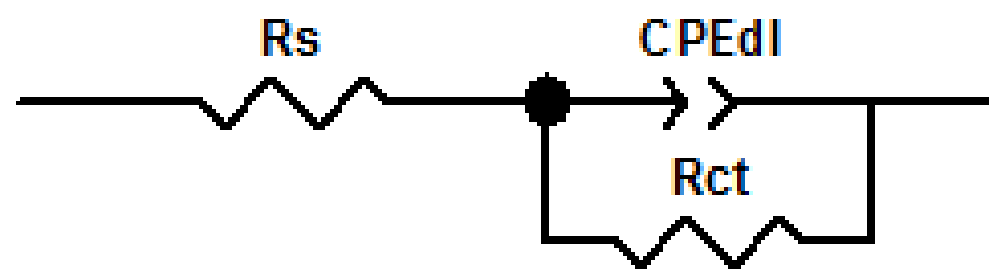

Figure 4: Equivalent electrical circuit used to fit the EIS diagrams for CS-1020 0.5 mol.L ${ }^{-1} \mathrm{HCl}$ solution without or with inhibitors.

Table 2: Results for the parameters obtained from the fitting of the EIS diagrams presented in Figure 3 with the equivalent electrical circuit of Figure 4.

\begin{tabular}{|c|c|c|c|c|c|c|}
\hline & $\begin{array}{l}\text { CONCENTRATION } \\
{\left[G . L^{-1}\right]}\end{array}$ & $\begin{array}{l}\text { RS } \\
{\left[\Omega . \mathrm{CM}^{2}\right]}\end{array}$ & $\begin{array}{l}\text { RCT } \\
{\left[\Omega \cdot \mathrm{CM}^{-2}\right]}\end{array}$ & $\begin{array}{l}\text { CPE-T } \\
{\left[\mathrm{F} . \mathrm{CM}^{-2} \mathbf{S}\left(\mathbf{N}^{-1}\right)\right]}\end{array}$ & $\alpha$ & IE\% \\
\hline $\begin{array}{l}\text { WITHOUT INHIBI- } \\
\text { TOR }\end{array}$ & - & 5,5 & 395 & 0,00026 & 0,74 & - \\
\hline $\begin{array}{l}\text { PEEL GARLIC EX- } \\
\text { TRACT }\end{array}$ & 1,112 & 7,2 & 2100 & $3,8 \mathrm{E}-05$ & 0,88 & 81,19 \\
\hline BTAH & 1,112 & 8,1 & 2292 & $3,6 \mathrm{E}-05$ & 0,89 & 82,28 \\
\hline
\end{tabular}

\subsubsection{Polarization Curves}

For each studied system, anodic and cathodic potentiodynamic polarization curves were obtained after the relaxation of the OCP to a stable value at the end of the EIS measurements. The curves are shown in Figure 5. 


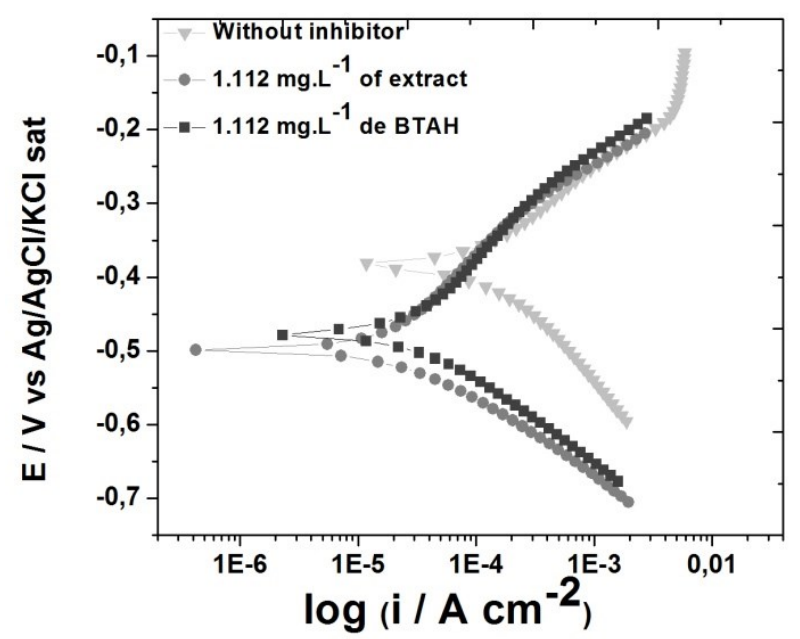

Figure 5: Polarization curves obtained for ASTM 1020 carbon steel after 110 min immersion in aqueous solution of 0.5 mol. $\mathrm{L}^{-1} \mathrm{HCl}$ without and with inhibitors.

Figure 5 demonstrates that both substances are cathodic type inhibitors and that their polarization behavior is very similar. Therefore, the hydrogen reduction reaction is hindered and the corrosion potential is shifted to the negative direction with a consequent diminution of corrosion current density. The curves of Figure 5 also show that all the cathodic branches are parallel, confirming that the addition of the inhibitors to the electrolyte does not change the cathodic reaction mechanism, just delaying it by the blocking effect. Afia et al. [19] reported mixed type inhibition for green garlic leaves extract. The differences in the results of these two works may be an indication of dissimilarities in the composition of the two extracts, which were obtained from different parts of the garlic plant. This had already been evidenced in the calculation of IE from the EIS measurements.

\subsection{Morphologic characterization by scanning electron microscopy (SEM)}

SEM images of CS-1020 surface were obtained before (Figure 6a) and after the completion of the electrochemical tests, totalizing $110 \mathrm{~min}$ of immersion in $0.5 \mathrm{~mol} . \mathrm{L}^{-1} \mathrm{HCl}$ in the absence (Figure $6 \mathrm{~b}$ ) and in the presence of $1.112 \mathrm{~g} \mathrm{~L}^{-1}$ of BTAH (Figure 6c) or $1.112 \mathrm{~g} \mathrm{~L}^{-1}$ of peel garlic extracts (Figure 6d). The comparative analysis of the micrographs show that in the solution without inhibitor the sample presents a generalized type of corrosion (Figure 6b), with anon-uniform precipitation of a relatively thick corrosion product layer. On the other hand, when immersed in the BTAH containing solution (Figure 6c), the formation of a corrosion product layer on the sample surface was not visible, whereas a localized type of corrosion could be detected. When the peel garlic extract was added to the solution, a thin and uniform corrosion product layer could be detected (Figure 6d). In the EDS analysis performed in this sample surface it was possible to identify peaks ascribed to "S" and "N", confirming the adsorption of the inhibitors molecule.
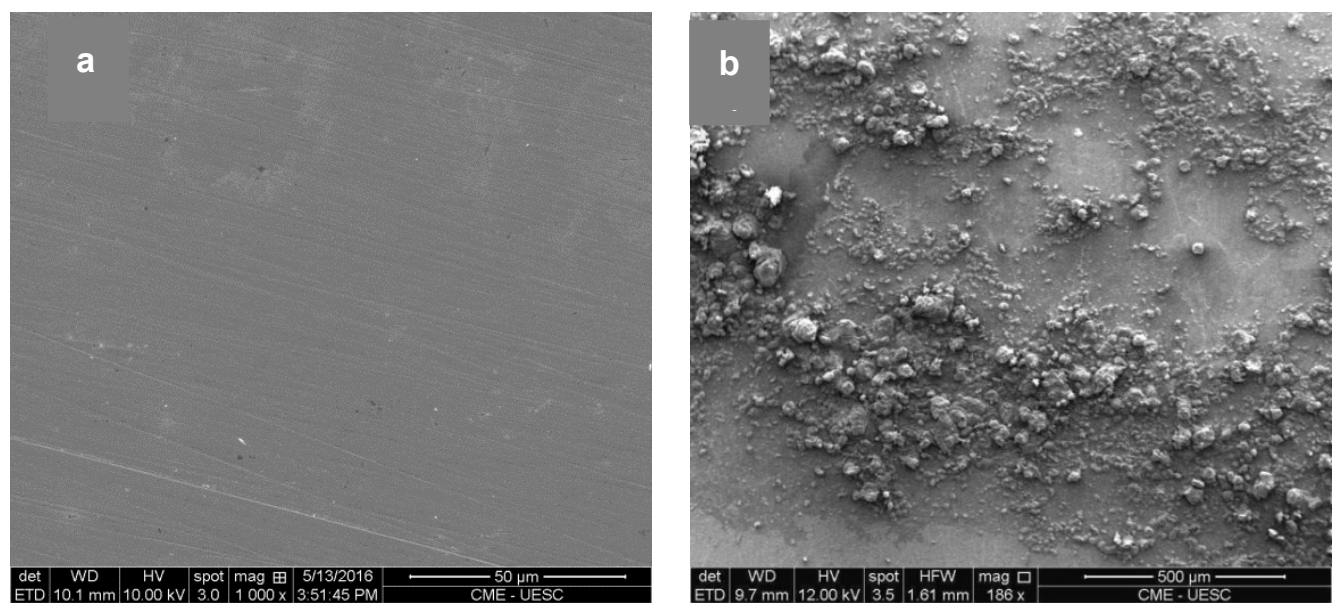

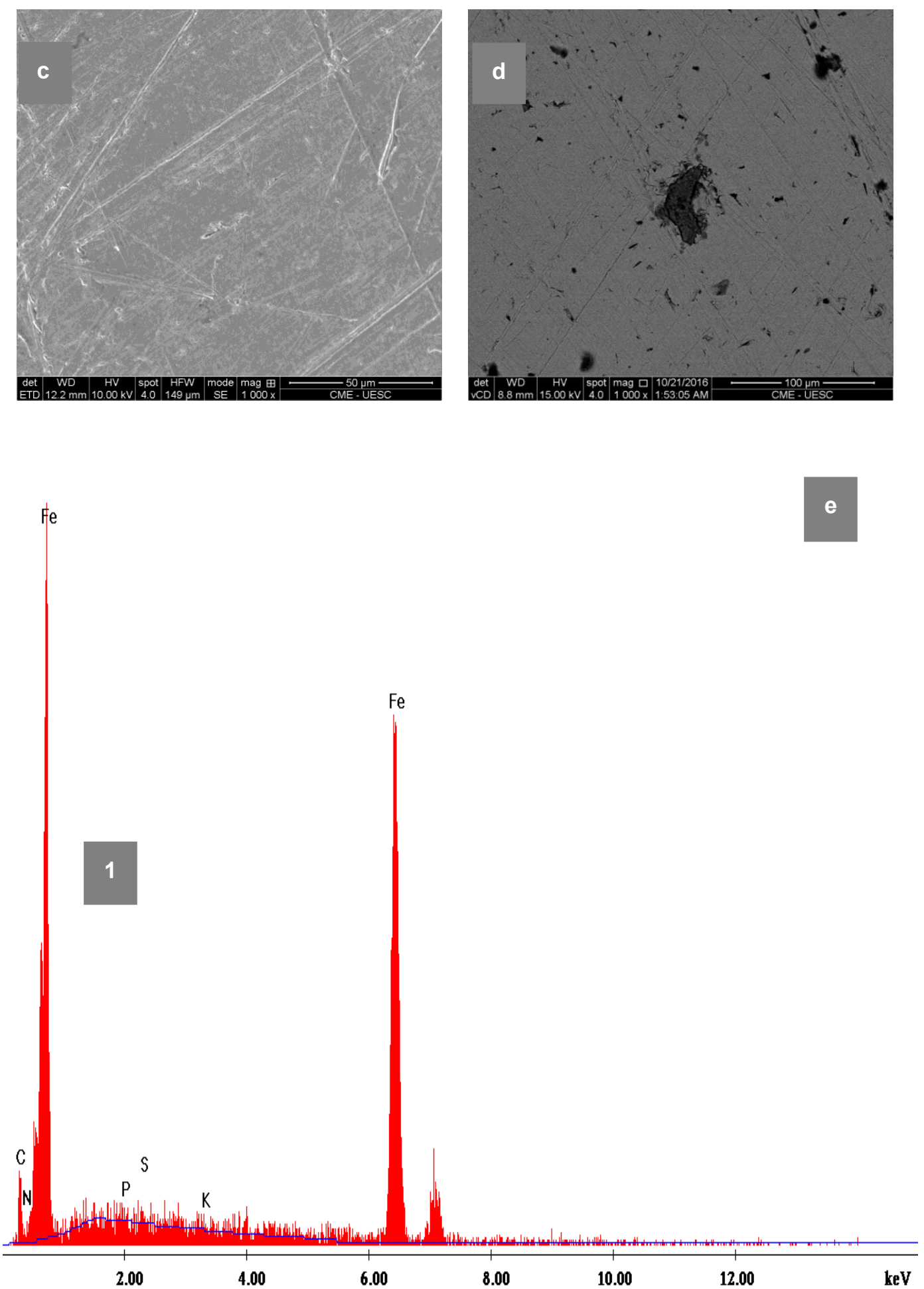

Figure 6: SEM images of ASTM 1020 carbon steel surface before (a) after $110 \mathrm{~min}$ immersion in $0.5 \mathrm{mol.L} \mathrm{L}^{-1} \mathrm{HCl}$ in the absence (b) and in the presence o benzatriazole (c) and peel garlic extract (d). EDS analysis of the sample surface after immersion in the solution containing peel garlic extract (e).

After the completion of the weight loss tests, totalizing $2 \mathrm{~h}$ of immersion in the different test electrolytes, SEM images (Figure 7) were also taken. As expected, for all samples, the attacked area and the density of precipitated corrosion products both increased when compared with the short immersion time tests. However, a clear difference still exists between the samples immersed in the inhibitor free and in the inhibitor containing solutions. In the former solution, a very dense corrosion product layer was formed all over the surface (Figure 7a). On the other hand, for the sample immersed in the peel garlic extract containing solution, 
heavy corrosion product formation was identified only at sparse regions (Figure 7c), whereas after immersion in the BTAH containing solution the localized attack of the sample surface has increased (Figure 7b). EDS analysis carried out in the surface of the sample immersed in the peel garlic extract containing solution (Figure $7 \mathrm{~d}$ ) showed nitrogen and sulfur peaks indicating that the inhibiting species still remain in the sample surface even after longer immersion times
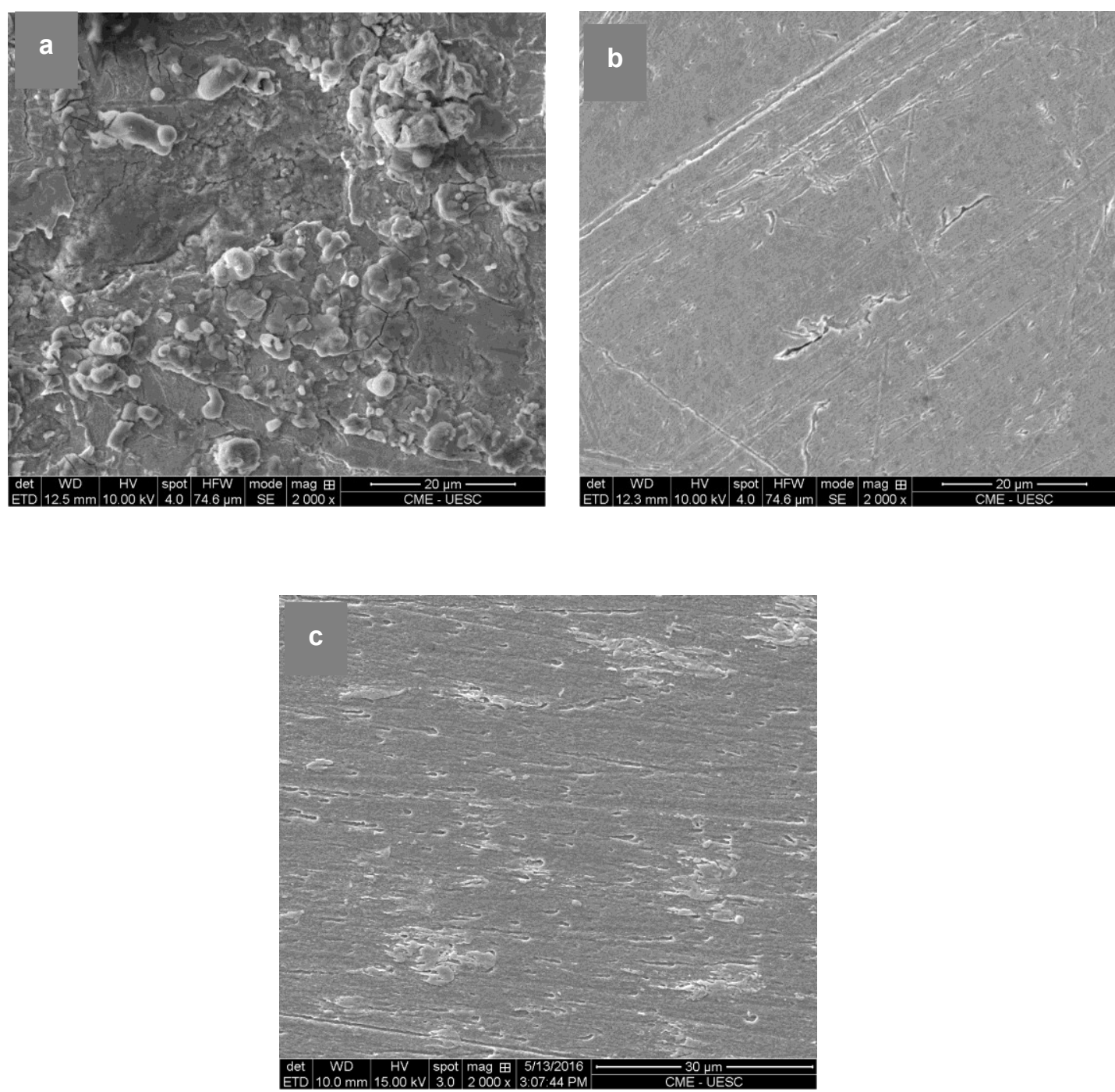


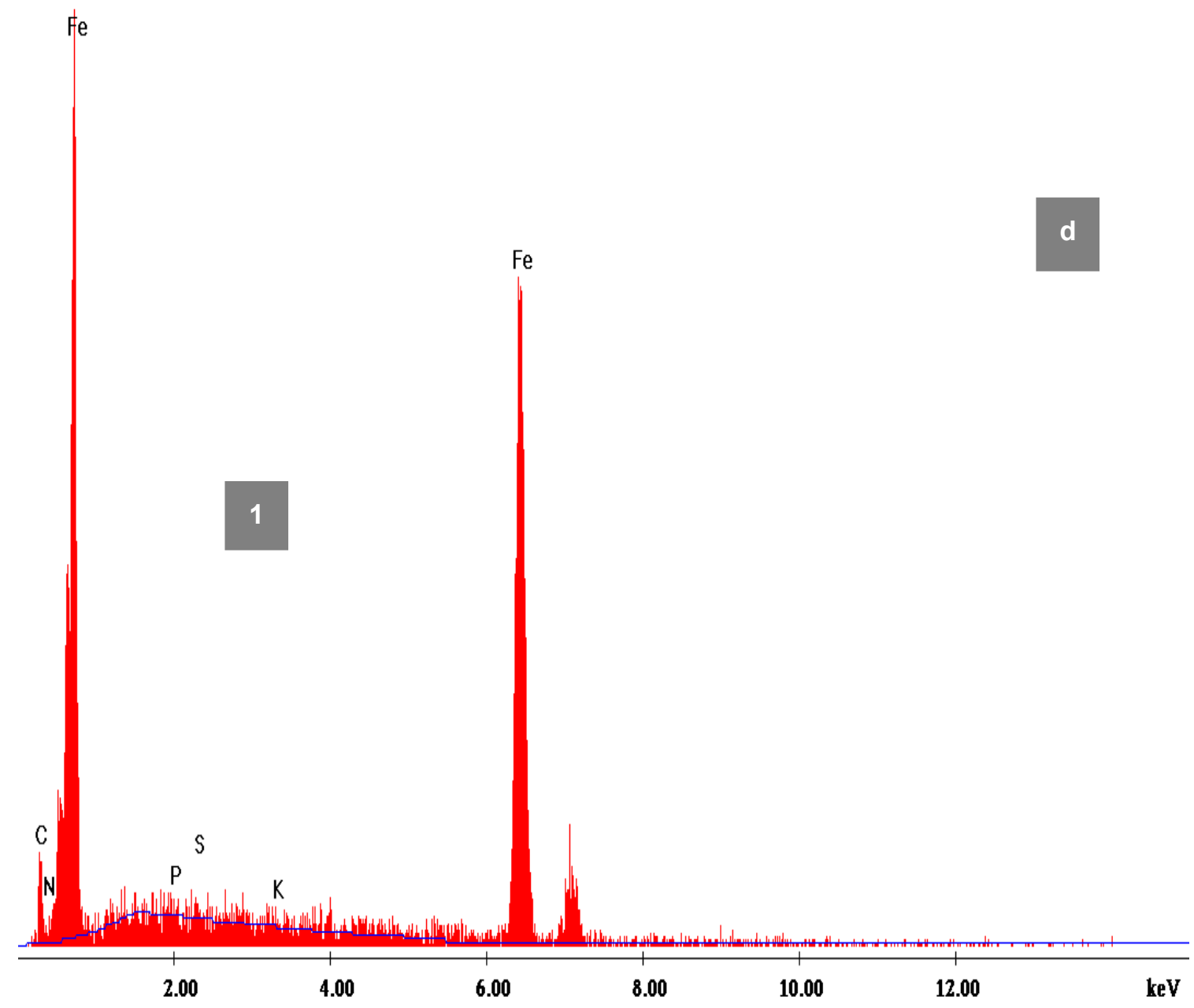

Figure 7: SEM images of ASTM 1020 carbon steel surface after $2 \mathrm{~h}$ immersion in 0.5 mol. $\mathrm{L}^{-1} \mathrm{HCl}$ in the absence (a) and in the presence of benzotriazole (b) and peel garlic extract (c). EDS analysis of the sample surface after immersion in the solution containing peel garlic extract (d).

\section{CONCLUSIONS}

In the present investigation, the effectiveness of peel garlic extract as a corrosion inhibitor for CS-1020 in 0.5 mol. $\mathrm{L}^{-1} \mathrm{HCl}$ solution was investigated and its efficiency compared with BTAH. FTIR characterization of the peel garlic extract powder showed the presence of nitrogen and sulfur containing compounds, which must act as active components in the inhibition process improving the adhesion of the molecules to the metallic surface.

The results of the electrochemical investigation showed that the tested inhibitors were effective in hindering the corrosion of CS-1020 and indicated that both inhibitors form an adsorbed layer on the CS-1020 surface hindering the corrosion process.

Inhibiting efficiency calculations from EIS experiments showed that the peel garlic extract is only slightly less efficient than BTAH in $0.5 \mathrm{~mol} . \mathrm{L}^{-1} \mathrm{HCl}$ solution showing that this green inhibitor can be an effective option to hinder corrosion of carbon steel in acidic media.

The inhibitor efficiency for peel garlic peel extract obtained in the weight loss was $90.65 \%$ and the corrosion rate $4.17 \times 10^{-5} \mathrm{~g} \cdot \mathrm{cm}^{-2} \cdot \mathrm{h}^{-1}$ while for BTAH the efficiency was $95.14 \%$ and the corrosion rate 2.64 $\mathrm{x} 10^{-5} \mathrm{~g} \cdot \mathrm{cm}^{-2} \cdot \mathrm{h}^{-1}$. These results showed that the peel garlic extract can be used as corrosion inhibitor.

The SEM images showed that the peel garlic extract slows down the progression of carbon steel corrosion rate. 


\section{ACKNOWLEDGEMENTS}

The authors would like to thank the following laboratories: LAMMA (Laboratory of Materials and Environment of the State University of Santa Cruz), BIOMA (Bioenergy and Environment) and CAPES (Higher Education Personnel Improvement Coordination) for the financial fostering.

\section{BIBLIOGRAPHY}

[1] CALlisteR, W. D., Ciência e Engenharia de Materiais: Uma introdução, 5 ed., São Paulo, Editora LTC, 2002.

[2] ADEYEMI, O.O., "Effect of Temperature and Concentration on Protective Action of 5 Membered Heterocycles on Acid Corrosion of Brass", Journal of Corrosion Science and Technology, v. 3, pp. 40-45, 2006.

[3] OGUIZE, E.E.,OKOLUE, B.N.,ONUCHUKWU, C.E. A.I., "Studies on the Inhibitive Action of MethyleneBlue Dye on Aluminium Corrosion in KOH Solution", Journal of Corrosion Science and Technology, v. 1, pp. 88-91, 2004.

[4] RODRIGUEZ, E.C., GONZALEZ, J.G.R ., VALLADARES, M.G.C., "Allium sativum as Corrosion Inhibitor for Carbon Steel in Sulfuric Acid", International Journal Electrochemical Science,v.9,pp. 5924 5936, 2014.

[5] BEN HMAMOU, D., AOUAD, M.R., SALGHI, R., et al., "Inhibition of C38 steel corrosion in hydrochloric acid solution by 4,5- Diphenyl-1H-Imidazole-2-Thiol: Gravimetric and temperature effects treatments", Journal of Chemical and Pharmaceutical Research , v. 4, n.7, pp. 3498, 2012.

[6] KHALED, K.F., "Molecular simulation, quantum chemical calculations and electrochemical studies for inhibition of mild steel by triazoles", Electrochemical Acta, v. 53, pp. 3484-3492, 2008.

[7] LAKE, D.L., "Approaching environmental acceptability in cooling water corrosion inhibition", Corrosion Prevents Control, v. 1, pp. 113-115, 1988.

[8] AYENI, F.A., et al. ,"Investigation of Sida acuta (Wire Weed) Plant Extract as Corrosion Inhibitor for Aluminium-Copper-Magnessium Alloy in Acidic Medium", Journal of Minerals and Materials Characterization and Engineering, v. 2, pp. 286-291, 2014.

[9] AMBRISH, M., SINGH, A., QURAISH, I., "The extract of Jamun (Syzygium cumini) seed as green corrosion inhibitor for acid media", Research on Chemical Intermediate, v. 41, pp. 2901-2914, 2015.

[10] ZERGA, B., SFAIRA, M., RAIS, Z., et al., "Lavender oil as an ecofriendly inhibitor for mild steel in 1 M HCl”, Materials' \& Techniques, v. 97, n. 5, pp. 297-305, 2009.

[11] FADEL, F., BEN HMAMOU, D., SALGHI, R., et al., "Antifungal activity and anti-corrosion inhibition of origanumcompactum extracts", International Journal Electrochemical Science, v. 8, pp. 11019 -11032, 2013.

[12] LOTO, C.A., "The Effect of Bitter leaf Extracts on Corrosion of Mild Steel in $0.5 \mathrm{M} \mathrm{HCl}$ and H2SO4 Solutions", Nigeria Corrosion Journal International, v. 1, pp. 19-20, 1998.

[13] AlSABAGH, A.M., MIGAHED, M.A., ABDELRAOUF, M., et al., "Utilization of Green Tea as Environmentally Friendly Corrosion Inhibitor for Carbon Steel in acidic media", International Journal Electrochemical Science, v. 10, pp. 1855 - 1872, 2015.

[14] FOUDA, A.S., ADDALLAH, Y.M., ELAWADY, G.Y., et al., "Electrochemical study on the effectively of Hyoscyamus Muticus Extract as a green inhibitor for corrosion of copper in 1 M HNO3", Journal of Materials and Environmental Science, v. 6, pp. 1519-1531, 2015.

[15] OBOT, I.B., OBI-EGBEDI, N.O., "An interesting and efficient green corrosion inhibitor for aluminium from extracts of Chlomolaena odorata L. in acidic solution", Journal of Applied Electrochemistry, v.40 pp. 1977-1984, 2010.

[16] SATAPATHY, A.K.,GUNASEKARAN, G., SAHOO, AMIT, et al., "Corrosion inhibition by Justicia gendarussa plant extract in hydrochloric acid solution”, Corrosion. Science, v. 51, pp. 2848-2856, 2012.

[17] MHYAWI, S.R.Al., "Corrosion Inhibition of Aluminum in $0.5 \mathrm{M} \mathrm{HCl}$ by Garlic Aqueous Extract", Journal of Chemistry, v. 30, n. 2, pp. 541-552, 2014. 
[18] LAKSHMI, P.S. CHITRA, A., RAJENDRAN, S., et al., "Corrosion behave our ofaluminum in rain water containing garlic extract”, Surface Engineering, v. 21 n. 3, pp, 229-231, 2005.

[19] AFIA, L., BENALI, O., SALGHI1, R., et al., "Steel Corrosion Inhibition by Acid Garlic Essential Oil as a Green Corrosion Inhibitor and Sorption Behavior", International Journal Electrochemical Science, v. 9, pp. $8392-8406,2014$.

[20] ASTM G1 (1999) Standard Practice for Preparing, Cleaning, and Evaluating Corrosion Test Specimens. [21] RAJAM, K., RAJENDRAN, S., SARANYA, R., "Allium Sativum (Garlic) Extract as Nontoxic Corrosion Inhibitor", Journal of Chemistry, pp. 743-807, http://dx.doi.org/10.1155/2013/743807, 2013.

[22] GOMES, A.W.M., Inibidores naturais de corrosão extraídos em vegetais, Tese de D.Sc., UNICAMP Campinas, SP, Brasil, 1999.

[23] ZUCCHI, F., OMAR, I.H., "Studies on the inhibitive effect of Occimum viridis extract on the acid corrosion of mild steel", Surface Technology, v.24, n. 4, pp. 391, 1985.

[24] HMAMOU, D. B., AOUAD,M. R., SALGHI, R., et al., "Inhibition of C38 steel corrosion in hydrochloric acid solution by 4,5- Diphenyl-1H-Imidazole-2-Thiol: Gravimetric and temperature effects treatments",Journal of Chemical and Pharmaceutical Research v. 4, n. 7, pp. 3498, 2012.

[25] XIAO, H., PARKIN, K. L., "Antioxidant Functions of Selected Allium Thiosulfinates and S-Alk(en)ylL-Cysteine Sulfoxides", Journal of Agricultural and Food Chemistry, v. 50, pp. 2488-2493, 2002.

[26] WANG, X., LIU, R., YANG, Y., ZHANG, M., "Isolation, purification and identification of antioxidants in an aqueous aged garlic extract”, Food Chemistry, v. 187, pp. 37-43, 2015.

[27] ZHANG, Z., TIAN, N., ZHANG, L., "Inhibition of the corrosion of carbon steel in $\mathrm{HCl}$ solution by methionine and its derivatives" Corrosion Science, v. 98, n. 14, pp. 438-449, 2015.

[28] TORRES, V.V., AMADO, R.S., DE SA, C.F., et al., Corrosion Science, v. 53, pp. 2385-2392, 2011.

[29] LOPEZ, D.A., SIMISON, S.N., SANCHEZ, S.R., "The influence of steel microstructure on CO2 corrosion. EIS studies on the inhibition efficiency of benzimidazole", Electrochimica Acta, v.48 pp. 845-854, 2003.

[30] FARSAK, M., KELES, H., KELES M.,"A new corrosion inhibitor for protection of low carbon steel in HCl solution”, Corrosion Science, v. 98 n. 25, pp. 223-232, 2015.

[31] ESPINOZA-VÁZQUEZ, A., NEGRÓN-SILVA,G., GONZÁLEZ-OLVERA, R., et al., "Mild steel corrosion inhibition in $\mathrm{HCl}$ by di-alkyl and di-1,2,3-triazole derivatives of uracil and thymine", Materials Chemistry and Physics, v. 145, pp. 407-417, 2014.

[32] GHAiLANE, T., BALKHMiMA, R.A., GHAILANE, R., et al., "Experimental and theoretical studies for mild steel corrosion inhibition in $1 \mathrm{M} \mathrm{HCl}$ by two new benzothiazine derivatives", Corrosion Science, v. 76, pp. 317-324, 2013.

[33] BANERJEE, S., SRIVASTAVA, V., SINGH, M.M., "Chemically modified natural polysaccharide as green corrosion inhibitor for mild steel in acidic medium” Corrosion Science, v. 59, pp. 35-41, 2012.

[34] ZAABBAR, A., AITOUT, R., MAKHLOUFI, L., et al., "Inhibition of acid corrosion of mild steel by aqueous nettle extracts", Pigment\& Resin Technology, v. 43, n. 3, pp. 127-138, 2014. 